\title{
ADAMTSI 3 Deficiency and Thrombotic Thrombocytopenic Purpura Associated with Trimethoprim-Sulfamethoxazole
}

\author{
Sowjanya Bapani, MD; Narendranath Epperla, MD; Yusuf Kasirye, MD; \\ Richard Mercier, MD; and Romel Garcia-Montilla, MD
}

\begin{abstract}
Thrombotic thrombocytopenic purpura (TTP) is a hematological disease characterized by microangiopathic hemolytic anemia and thrombocytopenia. Although the link between ADAMTSI 3 deficiency and idiopathic TTP has been well-established, the role of trimethoprimsulfamethoxazole (TMP-SMX) in the pathogenesis of TTP is not yet well elucidated. To the best of our knowledge, there have been only two previous reports linking this medication with the development of TTP. We present the case of a healthy woman, age 26 years, who developed TTP during TMP-SMX therapy for urinary tract infection. She was found to have ADAMTSI3 deficiency with anti-ADAMTSI 3 antibodies. Her condition responded to discontinuation of the TMP-SMX, plasmapheresis, and rituximab therapy. We speculate that the acquired ADAMTSI3 deficiency might have been triggered by the TMP-SMX therapy.
\end{abstract}

Keywords: ADAM proteins; Autoimmune Diseases/epidemiology; Purpura, Thrombotic

Thrombocytopenic; Trimethoprim-sulfamethoxazole

Corresponding Author:

Sowjanya Bapani, MD

Marshfield Clinic

Department of Internal Medicine

1000 North Oak Avenue

Marshfield, WI 54449

Tel: (7I5) 387-5260

Fax: (7I5) 389-5757

Email: bapani.sowjanya@marshfieldclinic.org

Received: June 27, 2012

Revised: November 15, 2012

Accepted: November 28, 2012

Published online ahead of print: December 21, 2012

doi: $10.3121 / \mathrm{cmr} .2012 .1105$

\section{Case Presentation}

A previously healthy woman, age 26 years, presented with abdominal pain, progressive fatigue, and purpuric skin rash over the extremities that began 7 days after beginning a treatment with trimethoprim-sulfamethoxazole (TMP-SMX) for a Klebsiella pneumoniae urinary tract infection. She also complained of exertional shortness of breath with no cough, hemoptysis, or other cardiopulmonary symptoms. No history of bleeding gums or hematochezia was present. A detailed interrogation did not demonstrate any other recent clinical complaints or the administration of any other type of medication beyond TMP-SMX. Physical examination revealed a young woman in no obvious distress, with a body mass index of 27 and stable vital signs. She had pallor and icterus of the mucus membranes but had no bleeding gums or rectal bleeding. She had a non-itchy, purpuric skin rash over her extremities, as well as petechiae. The rest of her physical examination was unremarkable.

Significant laboratory findings included a leucocyte count $6.5 \times 10^{3} / \mu \mathrm{L}$ [reference range $4.5-13.5 \times 10^{3} / \mu \mathrm{L}$ ], hemoglobin $8.9 \mathrm{~g} / \mathrm{dL}$ (which had been $12.7 \mathrm{~g} / \mathrm{dL}$ just one week earlier) [reference range 12.0-15.5 g/dL], hematocrit $25 \%$ [reference range $35-45 \%$ ], platelets $8,000 / \mathrm{mm}^{3}\left(314,000 / \mathrm{mm}^{3}\right.$ one week earlier) [reference range $150-450 \times 10^{3} / \mu \mathrm{L}$ ], and a creatinine level of $1.5 \mathrm{mg} / \mathrm{dL}$ [reference range 0.4-1.0 $\mathrm{mg} / \mathrm{dL}]$ which was elevated compared to her baseline value of $0.6 \mathrm{mg} / \mathrm{dL}$. Further workup showed lactate dehydrogenase (LDH) level of $797 \mathrm{U} / \mathrm{L}$ [reference range 81-190 U/L] and reticulocytes of 2.64\% [reference range 0.50-1.77\%]. Direct 


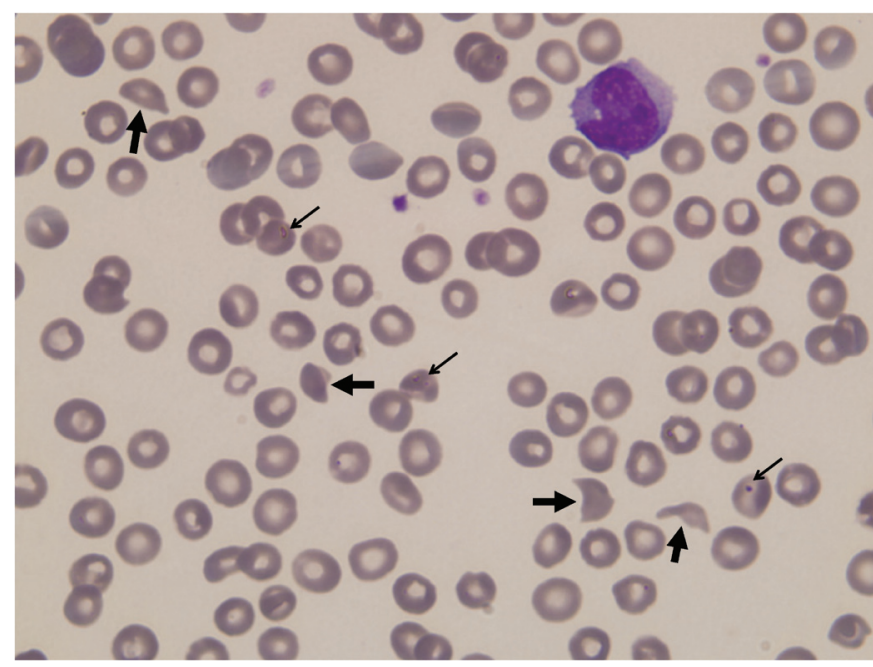

Figure 1. Peripheral blood smear with Wright Giemsa stain showing Schistocytes (large arrows), basophilic stippled erythrocytes (small arrows) and reduced number of platelets.

anti-globulin test as well as blood and urine cultures were negative. Transaminases and disseminated intravascular coagulation panel were all normal. A peripheral blood smear showed the characteristic findings of microangiopathic hemolytic anemia (figure 1).

Evaluation of ADAMTS13 (A Disintegrin $\underline{\text { And }}$ Metalloproteinase with ThromboSpondin motifs, 13) activity measured by fluorescence resonance energy transfer (FRET)- based kinetic assay was reported as less than 5\% [reference range $\geq 67 \%$ ]; levels less than $10 \%$ of normal activity make the diagnosis of severe deficiency. ${ }^{1}$ ADAMTS13 antibodies, measured using ELISA (enzyme-linked immunosorbant assay) were elevated at 1.2 inhibitor units [reference range: $\leq 0.4$ units].

The diagnosis of thrombotic thrombocytopenic purpura (TTP) was established, and plasmapheresis therapy was initiated. Five consecutive days of plasmapheresis before discharge were accomplished. This therapy was continued thereafter on an outpatient basis. After failure to achieve a complete hematological response with plasmapheresis, a 4-week course of rituximab was added, resulting in a complete clinical and hematological remission (figures 2 and 3). The ADAMTS13 enzyme assays done at the end of therapy with rituximab reported an activity of $94 \%$, with a platelet count of $282,000 / \mathrm{mm}^{3}$, hemoglobin $12.9 \mathrm{~g} / \mathrm{dL}$, and lactate dehydrogenase $167 \mathrm{U} / \mathrm{L}$. The patient remains in remission 8 months after discontinuation of plasmapheresis and rituximab therapies.

\section{Discussion}

Thrombotic thrombocytopenic purpura (TTP) is a type of thrombotic microangiopathy characterized by systemic microvascular platelet aggregation and erythrocyte destruction. Since it was first described by Moschcowitz in $1924,{ }^{2}$ our understanding of this unique syndrome has continuously evolved, especially from the etiologic viewpoint. The incidence, according to the Oklahoma TTP-HUS registry, is

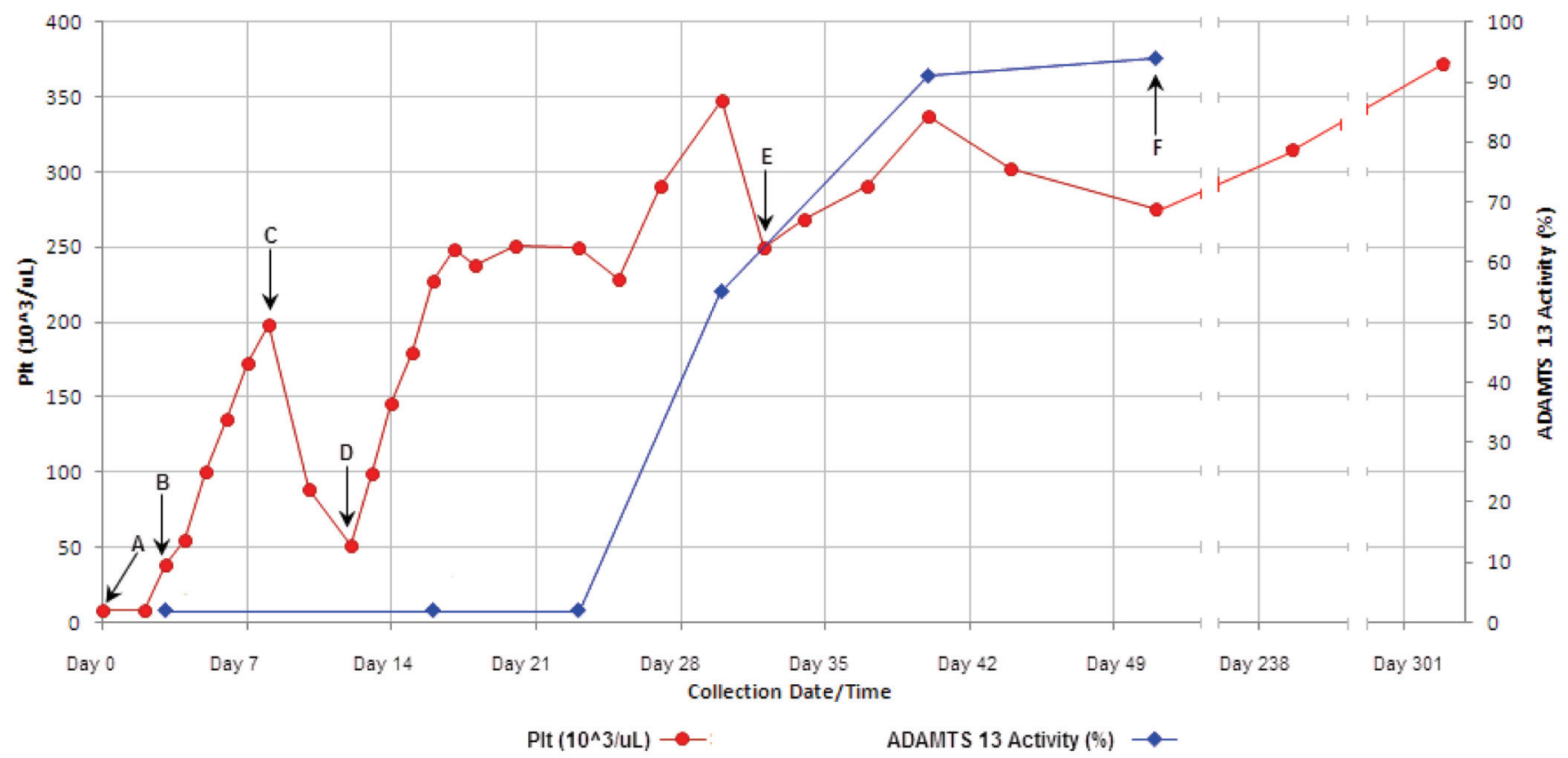

Figure 2. Platelet levels and ADAMTS 13 activity during the course of the disease. (A) Diagnosis of TTP was done, (B) Daily plasmapheresis therapy was started, (C) Plasmapheresis was switched to alternate day therapy, (D) Because of the significant new reduction in platelet count, daily plasmapheresis therapy was restarted, (E) Plasmaphersis was stopped. As an incomplete recovery of the ADAMTS 13 activity was made, rituximab therapy was initiated, (F) At the end of rituximab therapy ADAMTS 13 activity returned to normal levels. 


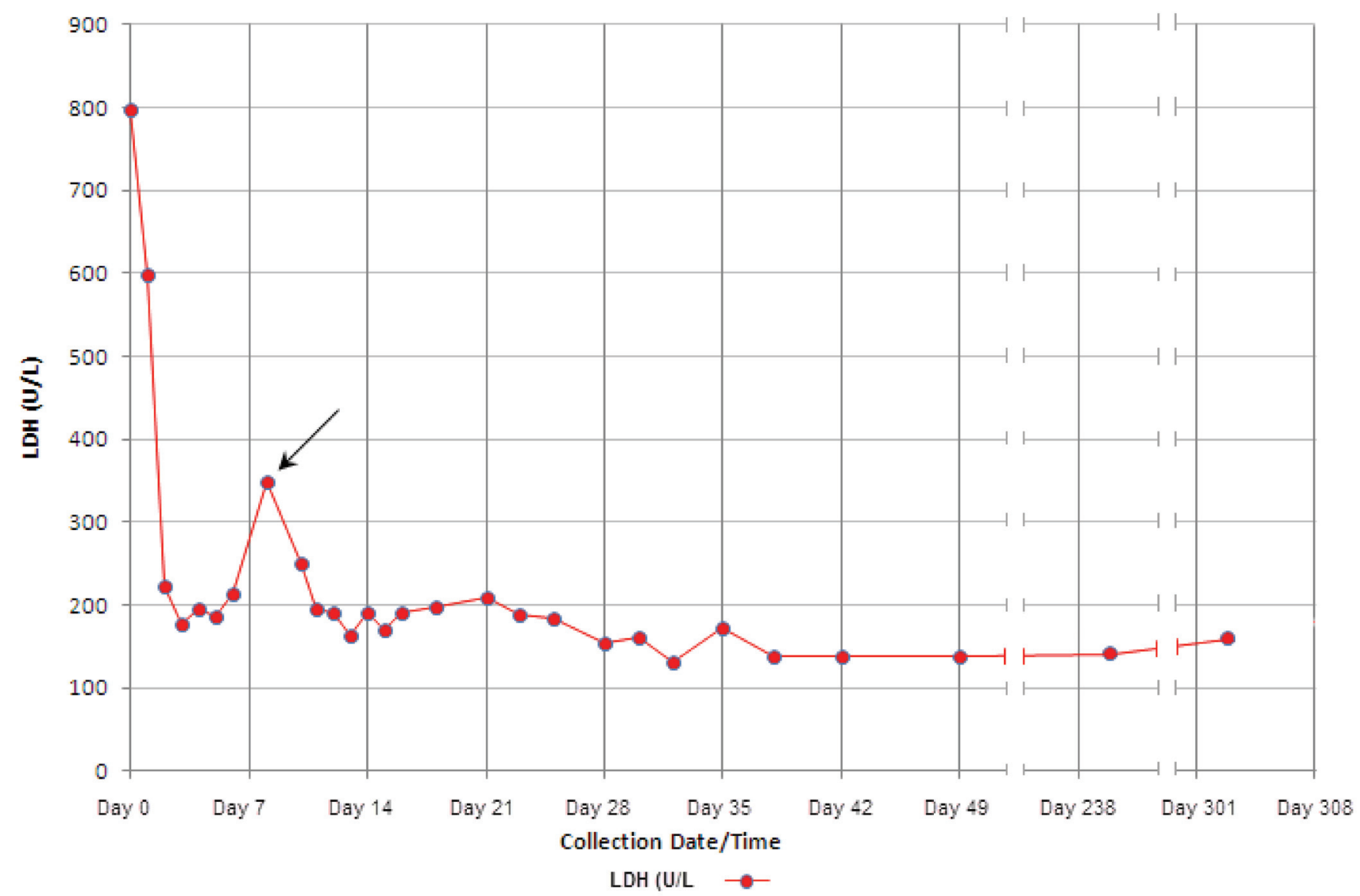

Figure 3. Lactate Dehydrogenase Levels. The new significant elevation observed (arrow) correlates with the period of time when plasmapheresis therapy had been switched to alternated days. A corresponding reduction on platelet count (figure 2D) required that the daily based plasmapheresis be restarted.

around 4 to 11 cases per million per year. TTP is characterized by systemic microvascular thrombi formation resulting in multi-organ damage, predominantly the skin, cardiac, renal, and central nervous systems. ${ }^{3-5}$ Historically, the diagnosis of TTP had relied on the presence of a pentad that included fever, microangiopathic hemolytic anemia, thrombocytopenia, renal failure, and central nervous involvement. ${ }^{5}$ However, at the present time, only the dyad of otherwise unexplained thrombocytopenia and microangiopathic hemolytic anemia is required to establish a diagnosis and initiate treatment. ${ }^{6}$

Thrombotic thrombocytopenic purpura can be congenital or acquired; ${ }^{6}$ the congenital type usually manifests in early childhood as chronic relapsing TTP. ${ }^{7}$ The etiology of acquired TTP is predominantly idiopathic, representing around $40 \%$ of all cases, ${ }^{8}$ but it can be associated with drugs, ${ }^{9,10}$ pregnancy, ${ }_{11}^{11}$ infections, ${ }^{12}$ and malignancies. ${ }^{13}$ The idiopathic type of TTP has been found to be related to a deficiency of a vital metalloproteinase enzyme referred to as ADAMTS13, which is responsible for the cleavage of the von Willebrand factor (vWF) multimers. ${ }^{14-17}$

Drug-associated TTP represents about $12 \%$ of all cases. ${ }^{8}$ The most common medications associated with TTP include quinine, thienopyridines, vaccines, H-2 receptor antagonists, nonsteroidal anti-inflammatory drugs, antineoplastic agents, and hormonal therapies. Antibiotics like cephalosporins, ampicillin, clarithromycin, metronidazole, oxytetracycline, penicillin, rifampicin, sulfisoxazole, and trimethoprimsulfamethoxazole have been also linked to the development of TTP. ${ }^{8-19}$

Drugs may cause TTP via two mechanisms: a dose related toxicity and/or an immune mediated reaction. ${ }^{9,10,18}$ In the particular association between TMP-SMX and TTP, very limited data is available to explain the possible mechanism by which TMP-SMX might be a trigger for TTP. There are three possible hypotheses. The first is that TMP-SMX causes an immune mediated injury to the small vessels, resulting in leucocytoclastic vasculitis that triggers a microangiopathic hemolytic process and eventually thrombosis. The second hypothesis is the likelihood that TMP-SMX-dependent antibodies destroy the ADAMTS 13, leading to the accumulation of vWF multimers and subsequently TTP. The third hypothesis is that TTP occurs as a complication of a hypersensitivity reaction to TMP-SMX. ${ }^{20-24}$

To the best of our knowledge, there are only two previous reports published linking TMP-SMX with TTP. One of those 
reports suggests that a hypersensitivity reaction involving diffuse endothelial injury or vasculitis is the most likely mechanism in the genesis of TTP, based on the normal level of ADAMTS13 activity and the absence of TMP-SMX dependent antibodies. ${ }^{20}$ The other report, which groups two cases, suggests that TTP associated with TMP-SMX is an idiosyncratic drug reaction, although neither ADAMTS 13 activity nor antibody levels or TMP-SMX dependent antibodies were evaluated. ${ }^{21}$ In our case, the patient was found to have a severe ADAMTS13 deficiency and inhibitory autoantibodies against ADAMTS13. These inhibitory antibodies are found in $44 \%$ to $93 \%$ of patients with acquired TTP and are believed to be involved in its pathogenesis. ${ }^{16,25,26}$ Their prognostic utility and the exact trigger for their production remains unknown. ${ }^{1,27}$ It is feasible to postulate that TMP-SMX could be one of those triggers, since it is a known stimulus for the formation of autoantibodies in other pathological processes ${ }^{28}$

We hypothesize that the exposure to TMP-SMX induced the generation of inhibitory autoantibodies, which in turn led to the accumulation of vWF multimers and eventually triggered the episode of TTP. Whether this relationship is legitimate or purely circumstantial remains a medical query that warrants more investigation.

\section{Acknowledgements}

The authors thank Marie Fleisner of the Marshfield Clinic Research Foundation's Office of Scientific Writing and Publication for editorial assistance in the preparation of this article.

\section{References}

1. Kremer Hovinga JA, Vesely SK, Terrell DR, Lämmle B, George JN. Survival and relapse in patients with Thrombotic thrombocytopenic purpura. Blood 2010;115:1500-1511.

2. Moschcowitz E. Hyaline thrombosis of the terminal arterioles and capillaries: a hitherto undescribed disease. Proc N Y Pathol Soc 1924;24:21-24.

3. George JN. Clinical practice. Thrombotic thrombocytopenic purpura. N Engl J Med. 2006;354:1927-1935.

4. Hawkins BM, Abu-Fadel M, Vesely SK, George JN. Clinical cardiac involvement in thrombotic thrombocytopenic purpura. Transfusion 2007;48:382-392.

5. Amorosi EL, Ultmann JE. Thrombotic thrombocytopenic purpura: report of 16 cases and review of the literature. Medicine (Baltimore) 1966;45:139-159.

6. Levy GG, Nichols WC, Lian EC, Foroud T, McClintick JN, McGee BM, Yang AY, Siemieniak DR, Stark KR, Gruppo R, Sarode R, Shurin SB, Chandrasekaran V, Stabler SP, Sabio H, Bouhassira EE, Upshaw JD Jr, Ginsburg D, Tsai HM. Mutations in a member of the ADAMTS gene family cause thrombotic thrombocytopenic purpura. Nature 2001; 413:488-494.

7. Furlan M, Robles R, Solenthaler M, Wassmer M, Sandoz P, Lämmle B. Deficient activity of von Willebrand factorcleaving protease in chronic relapsing thrombotic thrombocytopenic purpura. Blood 1997;89:3097-3103.

8. Terrell DR, Williams LA, Vesely SK, Lämmle B, Hovinga JA, George JN. The incidence of thrombotic thrombocytopenic purpura-hemolytic uremic syndrome: all patients, idiopathic patients, and patients with severe ADAMTS-13 deficiency. J Thromb Haemost 2005;3:1432-1436.
9. Zakarija A, Bennett C. Drug-induced thrombotic microangiopathy. Semin Thromb Hemost 2005;31:681-690.

10. Medina PJ, Sipols JM, George JN. Drug-associated thrombotic thrombocytopenic purpura-hemolytic uremic syndrome. Curr Opin Hematol 2001;8:286-293.

11. George JN. The association of pregnancy with thrombotic thrombocytopenic purpura-hemolytic uremic syndrome. Curr Opin Hematol 2003;10:339-344.

12. Gervasoni C, Ridolfo AL, Vaccarezza M, Parravicini C, Vago L, Adorni F, Cappelletti A, d'Arminio Monforte A, Galli M. Thrombotic microangiopathy in patients with acquired immunodeficiency syndrome before and during the era of introduction of highly active antiretroviral therapy. Clin Infect Dis 2002;35:1534-1540.

13. Antman KH, Skarin AT, Mayer RJ, Hargreaves HK, Canellos GP. Microangiopathic hemolytic anemia and cancer: a review. Medicine (Baltimore) 1979;58:377-384.

14. Sadler JE. Von Willebrand factor, ADAMTS13, and thrombotic thrombocytopenic purpura. Blood 2008;112:1118.

15. Furlan M, Robles R, Galbusera M, Remuzzi G, Kyrle PA, Brenner B, Krause M, Scharrer I, Aumann V, Mittler U, Solenthaler M, Lämmle B. Von Willebrand factor-cleaving protease in thrombotic thrombocytopenic purpura and the hemolytic uremic syndrome. New Engl J Med 1998;339:1578-1584.

16. Tsai HM, Lian EC. Antibodies to von-Willebrand factorcleaving protease in acute thrombotic thrombocytopenic purpura. New Eng J Med 1998;339:1585-1594.

17. Vesely SK, George JN, Lämmle B, Studt JD, Alberio L, El-Harake MA, Raskob GE. ADAMTS13 activity in thrombotic thrombocytopenic purpura-hemolytic uremic syndrome: relation to presenting features and clinical outcomes in a prospective cohort of 142 patients. Blood 2003;101:60-68.

18. Kojouri K, Vesely SK, George JN. Quinine-associated thrombotic thrombocytopenic purpura-hemolytic uremic syndrome: frequency, clinical features, and long-term outcomes. Ann Int Med 2001;135:1047-1051.

19. Baron BW, van Besien K, Hoffman PC, Kohn OF, Rossof AH, Baron JM. Transfusion 2003;43:1317-1321.

20. Martin MG, Whitlatch NL, Shah B, Arepally GM. Thrombotic thrombocytopenic purpura induced by trimethoprimsulfamethoxazole in a Jehovah's Witness. Am J Hematol 2007;82:679-681.

21. Herrington A, Mahmood A, Berger R. Treatment options in sulfamethoxazole-trimethoprim-induced thrombocytopenic purpura. South Med J 1994;87:948-950.

22. Feiza BA, Samy F, Asma D, Rym B, Insaf M. [Article in French] Urticarian vasculitis. A case report after sulfamethoxazole-triméthoprime ingestion. Tunis Med 2005;83:714-716

23. Sen S, Bayrak R, Ok E, Başdemir G. Drug-induced acute interstitial nephritis and vasculitis or vasculary rejection in renal allografts. Am J Kidney Dis 2001;37:E4.

24. Israel HL. Sulfamethoxazole-trimethoprim therapy for Wegener's granulomatosis. Arch Intern Med 1988; 148:2293-2295.

25. Yamaguchi Y, Moriki T, Igari A, Nakagawa T, Wada H, Matsumoto M, Fujimura Y, Murata M. Epitope analysis of autoantibodies to ADAMTS13 in patients with acquired thrombotic thrombocytopenic purpura. Thromb Res 2011;128:169-173.

26. Shelat SG, Smith P, Ai J, Zheng XL. Inhibitory autoantibodies against ADAMTS-13 in patients with thrombotic thrombocytopenic purpura bind ADAMTS-13 protease and may accelerate its clearance in vivo. J Thromb Haemost 2006;4:1707-1717. 
27. Peyvandi F, Lavoretano S, Palla R, Feys HB, Vanhoorelbeke K, Battaglioli T, Valsecchi C, Canciani MT, Fabris F, Zver S,

Réti M, Mikovic D, Karimi M, Giuffrida G, Laurenti L,

Mannucci PM. ADAMTS13 and anti-ADAMTS13 antibodies

as markers for recurrence of acquired thrombotic

thrombocytopenic purpura during remission. Haematologica 2008;93:232-239.

28. Ermis B, Caner I, Karacan M, Olgun H. Haemolytic anaemia secondary to trimethoprim/sulfamethoxazole use. Thromb Haemost 2003;90:158-159.

\section{Author Affiliations}

Sowjanya Bapani, MD*; Narendranath Epperla, MD*;

Yusuf Kasirye, $M D^{*}$; Richard Mercier, $\mathrm{MD}^{+}$;

Romel Garcia-Montilla, MD*

*Department of Internal Medicine, Marshfield Clinic,

Marshfield, Wisconsin USA

'Department of Hematology-Oncology, Marshfield Clinic,

Marshfield, Wisconsin USA 